\title{
Plasma Arc Melting (PAM) and Corrosion Resistance of Pure NiTi Shape Memory Alloys
}

\author{
A. Tuissi ${ }^{1} \cdot$ G. Rondelli ${ }^{2} \cdot$ P. Bassani ${ }^{1}$
}

Published online: 21 April 2015

(C) ASM International 2015

\begin{abstract}
Plasma arc melting (PAM) as a suitable noncontaminating melting route for manufacturing high-quality NiTi alloy was successfully examined. The corrosion resistance of PAM Nitinol was evaluated by both potentiodynamic and potentiostatic tests and compared with lower purity NiTi produced by vacuum induction melting (VIM). For the electro-polished surfaces, excellent corrosion resistance of NiTi comparable with the Ti alloys was found with no pitting up to $800 \mathrm{mV}$ versus saturated calomel electrode in simulated body fluid at $37^{\circ} \mathrm{C}$. Potentiostatic results of PAM Nitinol indicate slightly better corrosion resistance than the lower quality VIM alloy.
\end{abstract}

Keywords NiTi processing - Corrosion resistance . Plasma arc melting $\cdot$ Microstructure

\section{Introduction}

Due to the highly reactive nature of titanium, the synthesis of NiTi shape memory alloy (also known as Nitinol) requires non-contaminating processing methods. The gathering of $\mathrm{C}, \mathrm{N}$, and $\mathrm{O}$ on melting causes the formation of inclusions such as $\mathrm{TiC}, \mathrm{TiO}_{2}$, and $\mathrm{Ti}_{2} \mathrm{Ni}_{x} \mathrm{O}_{y}$ on bulk level and hot-working oxidation may leave distributed inclusions

A. Tuissi

tuissi@ieni.cnr.it

1 CNR IENI Unit of Lecco, National Research Council of Italy - Institute for Energetics and Interphases, Corso Promessi Sposi 29, 23900 Lecco, Italy

2 CNR IENI Unit of Milan, National Research Council of Italy - Institute for Energetics and Interphases, Via R. Cozzi 53, 20125 Milan, Italy at surface level of semi-finished products. A recent observation, the surface particulates of NiTi and in biomedical devices, is reported by Shabalovskaya et al. [1]. The inclusions, and their sizes, could affect both the NiTi functional properties and the processing aspects such as the workability of low dimension semi-finished products. Nowadays, the role and the amount of inclusions affecting specific properties such as the fatigue life, biocompatibility, or corrosion resistance of devices made in NiTi are not univocally explained. Regarding TiC inclusions, which are found typically in VIM processed Nitinol due to carbon crucibles employed in this kind of melting plant, their presence is particularly detrimental to pitting corrosion resistance, as asserted in Kimura and Sohmura [2], Shabalovskaya et al. [3]. Also, regarding oxide-type inclusions (i.e., $\mathrm{Ti}_{2} \mathrm{NiO}_{x}$ ) Liang and Huang [4] have found that their presence is the main reason for pitting. Coda et al. [5] characterized the main types of inclusions of commercial Nitinol produced by VIM and vacuum arc melting (VAR) routes; by means of extreme value statistics, Urbano et al. [6] showed that the maximum inclusion dimension in the highly strained volume of a fatigue test contributes to a decrease in the fatigue performance of 0.3mm-diameter superelastic wires. Morgan et al. [7] reported about extra low inclusions content (ELI) alloys appeared to have improved fatigue performances. Rahim et al. [8] investigated the effect of $\mathrm{C}$ and $\mathrm{O}$ impurity levels on fatigue lives, of pseudoelastic NiTi, reporting that the fatigue resistance is affected mainly by surface aspects and that lower $\mathrm{C}$ and $\mathrm{O}$ contents will not result in greater fatigue lives. However, cleaner processing decreases the probability for fatigue crack initiation due to inclusions, but it cannot suppress it completely. It is a matter of fact that non-contaminating melting route should be used for the production of high-quality $\mathrm{NiTi}$ alloys for biomedical 
applications, according to the ASTM standard specification F 2063-12 [9] that limits both the impurity contents as well as the amount of particulates. Among non-contaminating melting methods, PAM represents one of the most important achievements in the field of high-quality alloy production over the last three decades. The elevated working pressure of PAM prevents the selective evaporation of the high-vapor pressure elements avoiding chemical alterations of final alloys composition. Moreover, inert operating conditions of PAM, in conjunction with the transfer of a high energy density, permit alloying of a great number of metallic elements. For over 20 years, industrial PAM furnaces have been employed for the production of reactive, high melting points, refractory metals, and superalloys, as reported in [10-15]. Thus, PAM seems particularly suitable for melting "cleaner," near equiatomic NiTi shape memory alloys (SMA), not only on laboratory scale NiTi-based button preparations [16, 17], but also for Nitinol industrial production.

The aim of this work is the evaluation of the corrosion resistance of a $\mathrm{Ni}_{50.8} \mathrm{Ti}_{49.2}$ alloy produced by a pilot scale PAM furnace in comparison to one prepared through a conventional VIM melting technique by using the same starting $\mathrm{Ni}$ and $\mathrm{Ti}$ metals. Microstructures of PAM and VIM NiTi alloys were investigated by FEG-SEM, and the corrosion resistance was determined by potentiodynamic as well as potentiostatic tests in a simulated body fluid (SBF) solution.

\section{Experimental}

\section{NiTi Melting and Processing}

Commercially pure Ti rods, $3 \mathrm{~mm}$ in diameter (ASTM grade 1-Titania srl) with typical impurities content of $\mathrm{N}$ 100; C 200; H 26; Fe 500; O 600 ppm; and electrolytic Ni (Falconbridge ${ }^{\mathrm{TM}}>99.99 \%$ : $\mathrm{Cu}, \mathrm{Co}, \mathrm{Fe}, \mathrm{Pb}, \mathrm{S}, \mathrm{Zn}$ $<5 \mathrm{ppm}$ ) were chosen as starting metals. It is worth noting that the ASTM F67 standard specification for unalloyed titanium for surgical implant accepts greater oxygen (up to $1800 \mathrm{ppm}$ ) and carbon (up to $800 \mathrm{ppm}$ ) contents for grade 1 Ti. So the chosen starting metals assure a detectable amount of endogenous forced inclusions into the NiTi alloys produced by PAM and VIM plants of this work. A Nirich nominal composition of $\mathrm{Ni}_{50.8} \mathrm{Ti}_{49.2}$ (at.\%) was selected for guaranteeing the austenitic state at body temperature, required for developing superelastic medical devices.

PAM NiTi was produced by a laboratory scale plasma arc furnace (Leybold-Plasma Lab $300{ }^{\mathrm{TM}}$ ) equipped with a transferred plasma torch of $150 \mathrm{~kW}$ (PEC Plasma Electric Company $\left.{ }^{\circledR}\right)$. Feeding materials were drip melted into a cylindrical (60 mm dia.) water-cooled, copper crucible, under pure He (purity $>99,995$ ) atmosphere. An ingot of $400 \mathrm{~mm}$ in length was processed by continuous casting. The PAM ingot was then re-melted 5 times by drip melting for increasing compositional homogeneity.

As comparison, a low-purity NiTi ingot of the same $\mathrm{Ni}_{50.8} \mathrm{Ti}_{49.2}$ (at.\%) nominal composition was melted in a VIM furnace (Balzers VSG10 ${ }^{\mathrm{TM}}$ ) in a dense graphite crucible using the same starting $\mathrm{Ni}$ and Ti metals. Then, the VIM material was cast in a water-cooled copper mold. Details of both PAM and VIM laboratory plants employed for small productions were reported elsewhere [18, 19]. After melting, the two PAM and VIM NiTi ingots were hot forged at $900{ }^{\circ} \mathrm{C}$ in air to rods $20 \mathrm{~mm}$ in diameter. Then the rods were fully annealed at $900{ }^{\circ} \mathrm{C}$ for $2 \mathrm{~h}$ and water quenched.

\section{Material Characterization Techniques}

The non-metallic $\mathrm{C}, \mathrm{O}$, and $\mathrm{N}$ impurities of the fully annealed produced NiTi rods were measured with LECO analyzers. Transformation temperatures of PAM and VIM NiTi specimens taken from fully annealed NiTi rods were checked by a differential scanning calorimeter (DSC-TA Instruments $\mathrm{Q} 100^{\mathrm{TM}}$ ) at heating/cooling rate of $10{ }^{\circ} \mathrm{C} \mathrm{min}^{-1}$. Cross and longitudinal sections of the PAM and VIM rods were cut with a metallographic saw and then were prepared with standard metallographic polishing to $1 \mu \mathrm{m}$ diamond cloth. Scanning electron microscope investigation was conducted using a FEG-SEM (Hitachi SU$70^{\mathrm{TM}}$ ) equipped with SE, BSE and EDS detectors.

\section{Corrosion Resistance Analysis}

For the corrosion resistance tests, cylindrical specimens $15 \mathrm{~mm}$ in dia. and $6 \mathrm{~mm}$ high were machined from the PAM and VIM rods. Due to the well-known effect of surface roughness on the corrosion resistance, the surfaces of the samples were prepared using emery paper mechanical polishing (MP), diamond clothes polishing $(1 \mu \mathrm{m}$ MP) as well as electro-polishing (EP) in a perchloric acid $10 \%$ butylene glycol $90 \%$ solution at applied voltage of $40 \mathrm{~V}$ for $120 \mathrm{~s}$. Three surface finish conditions were investigated:

\section{(a) \#600 Grit emery paper (\#600 MP).}

(b) $1 \mu \mathrm{m}$ diamond clothes polishing $(1 \mu \mathrm{m} \mathrm{MP})$.

(c) $1 \mu \mathrm{m}$ diamond clothes + electro-polishing $(1 \mu \mathrm{m}$ $\mathrm{EP})$.

All the corrosion tests were performed in a SBF solution with the following composition: $\mathrm{NaCl} 8.44 \mathrm{~g} / \mathrm{L}, \mathrm{NaHCO}_{3}$ $0.35 \mathrm{~g} / \mathrm{L}, \mathrm{NaHPO}_{4} 0.06 \mathrm{~g} / \mathrm{L}$, and $\mathrm{NaH}_{2} \mathrm{PO}_{4} 0.06 \mathrm{~g} / \mathrm{L}$. The solution was maintained at constant temperature of $37{ }^{\circ} \mathrm{C}$ 
and protected by an extremely high purity nitrogen gas flow.

Cycling potentiodynamic tests were performed using the experimental apparatus suggested in ASTM G5 Standard practice [20]. A specimen holder for flat specimens according to ASTM G61 Standard practice [21] was used (exposed area $1 \mathrm{~cm}^{2}$ ). The specimen was immersed in the test solution for $1 \mathrm{~h}$ before potentiodynamic scanning. Initial potential was $600 \mathrm{mV}$ versus saturated calomel electrode (SCE), and scan rate was $600 \mathrm{mV} / \mathrm{h}$. Reversal of the scanning direction was done when the anodic current density reached $100 \mu \mathrm{A} / \mathrm{cm}^{2}$. The reference electrode was a home-made $\mathrm{Ag}-\mathrm{AgCl}$ electrode, and the potential was then expressed as SCE values. The tests were re-done at least in triplicate.

Potentiostatic scratch tests were performed also using the same electrode assembly for flat specimen as described above. In the scratch method originally proposed by Pessal and Liu [22], the metal surface is slightly damaged using a diamond tip while the potential is maintained constant. If the specimen reaches the passivation state under the applied potential value, the scratching test is repeated by applying an increased (in $10 \mathrm{mV}$ steps) potential value so that the potential at which the material does not re-passivate can be determined.

\section{Results and Discussion}

\section{Non-metallic Impurities and DSC}

Oxygen, carbon, and nitrogen contents were analyzed in different regions of the fully annealed rods used for corrosion resistance tests. $\mathrm{C}, \mathrm{O}$, and $\mathrm{N}$ average values of five measurements for each non-metallic impurity are summarized in Table 1.

As expected, lower non-metallic impurity contents are found in PAM NiTi. These values are consistent with the impurity level of the starting Ti and confirm the extraordinary non-contaminating characteristic of PAM melting route. On the contrary, VIM NiTi shows greater $\mathrm{C}$ and $\mathrm{O}$ contents than commercially available Nitinol resulting in an elevated impurities gathering effects. That is due to some unavoidable features related to the VIM melting method: (i) a direct pickup of $\mathrm{C}$ by liquid alloy contained in the graphite crucible; (ii) the reaction between the graphite

Table 1 Average O, C, and N contents of PAM and VIM NiTi rods

\begin{tabular}{lll}
\hline Element $(\mathrm{wt} \%)$ & PAM Ni $\mathrm{N}_{50.8} \mathrm{Ti}_{49.2}$ & $\mathrm{VIM} \mathrm{Ni}_{50.8} \mathrm{Ti}_{49.2}$ \\
\hline $\mathrm{O}$ & 0.0311 & 0.0680 \\
$\mathrm{C}$ & 0.0094 & 0.0596 \\
$\mathrm{~N}$ & 0.0032 & 0.0031 \\
\hline
\end{tabular}

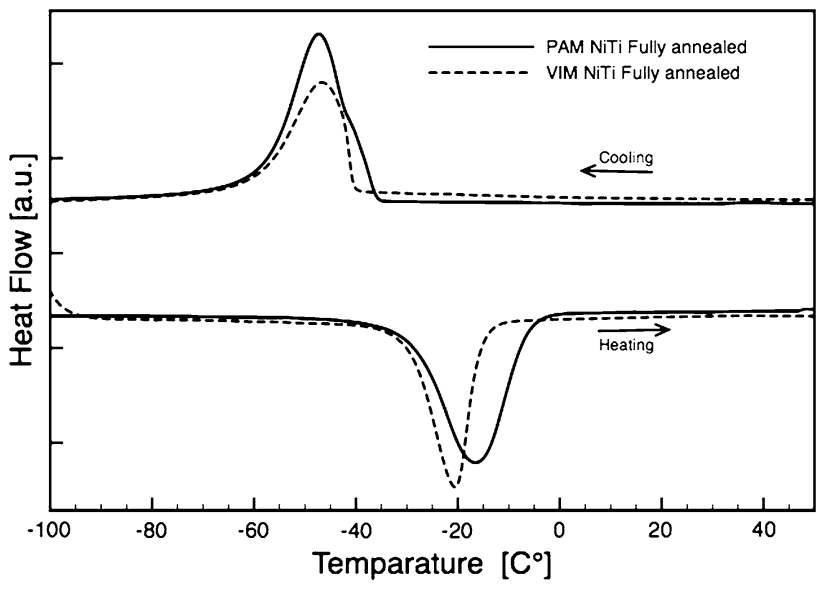

Fig. 1 DSC curves (heating/cooling rate $10{ }^{\circ} \mathrm{C} / \mathrm{min}$ ) of PAM and VIM Ni50.8Ti49.2 fully annealed specimens

crucible and the surrounding $\mathrm{Al}_{2} \mathrm{O}_{3}$-based concrete used as thermal insulation and crucible holder that can produce $\mathrm{CO}$ and $\mathrm{CO}_{2}$; these products could be accumulated into the alloy; (iii) the residual humidity of both the graphite crucible and the insulating concrete that can be absorbed by the reactive Ti upon heating and by liquid NiTi during soaking and casting times. For both the alloys, the total $\mathrm{N}$ content is negligible.

It is worth noting that the detected impurity values of VIM NiTi exceed the limits of the active standard ASTM F2063 that, for biomedical applications, reasonably, restricts the amount of both carbon and oxygen + nitrogen impurities of wrought NiTi up to $500 \mathrm{ppm}$ [9]. In any case for this work, suitable standard purity PAM and a low purity VIM NiTi alloys were realized for studying the effect of different inclusions levels on Nitinol corrosion resistance characteristics.

DSC results, of specimens taken from fully annealed rods of PAM and VIM materials, show typical reversible martensitic transformation curves with austenite finish temperature, $A_{f}$, below $0{ }^{\circ} \mathrm{C}$ (see Fig. 1). The broader DSC peaks of PAM alloy compare to those of the VIM NiTi are indicative of a minor compositional homogeneity of the $\mathrm{NiTi}$ alloy. This is due to the laboratory scale, single torch, PAM furnace used in this work that cannot guarantee the same chemical homogeneity of VIM melting alloys. The latter is quite good thanks to the magnetic stirring effect during VIM melting. Similar homogeneity degree can be reached by multiple torches PAM furnaces, as employed in the industrial production of Ti alloys.

\section{Microstructure and Particles Statistical Analysis}

The nature, distribution, and size of particulates and secondary phases in PAM and VIM alloys were analyzed through SEM observation with backscattered electron 
detector. Selected images are reported in Fig. 2. PAM NiTi revealed two populations of secondary phases with different sizes. The predominant phase, of very small size, was localized at grain boundaries. EDS analyses revealed Ti/Ni
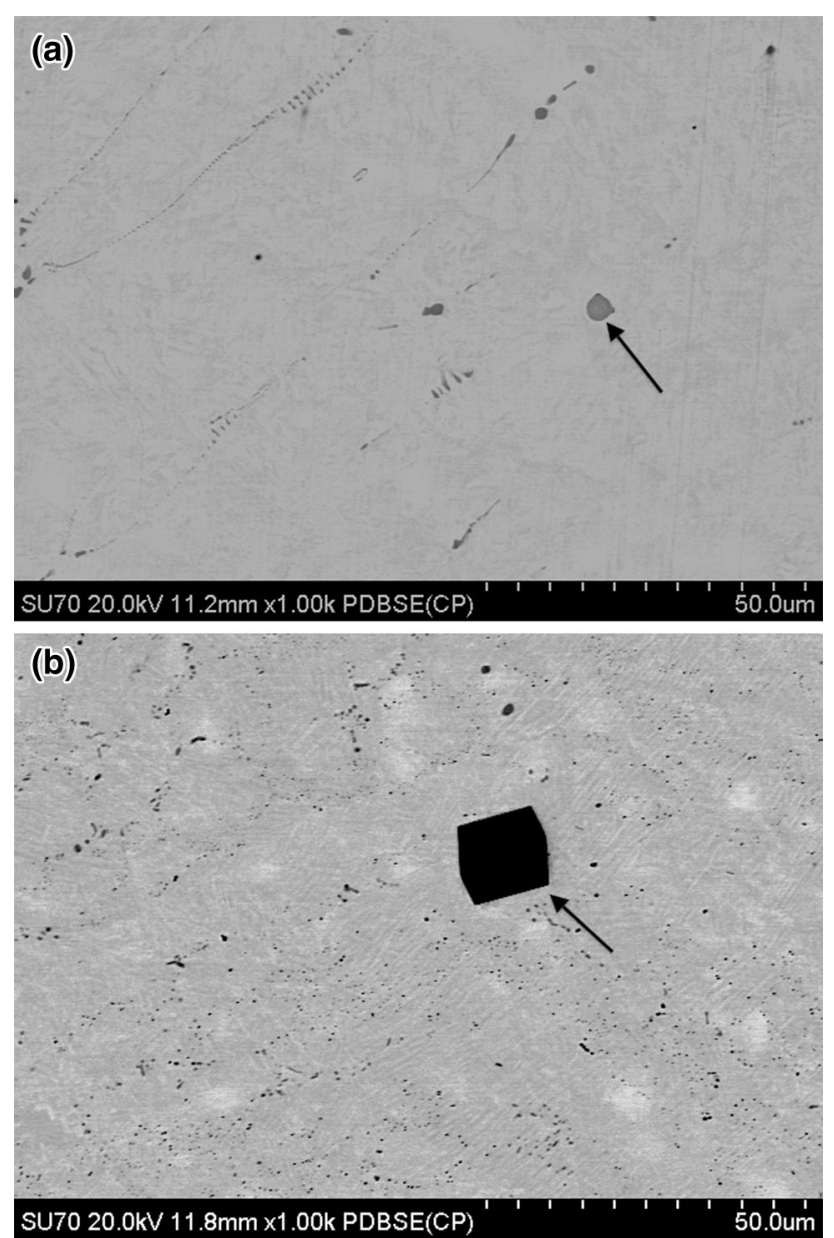

Fig. 2 SEM micrographs of PAM (a) and VIM (b) of Ni50.8Ti49.2 rods after hot rolling and fully annealing. The arrows show typical inclusions ratios of 2:1. The oxygen content was not easily assessed by EDX, but varied from one particle to another. Hence, $\mathrm{Ti}_{2} \mathrm{Ni}$ intermetallic phase and $\mathrm{Ti}_{2} \mathrm{Ni}_{\mathrm{x}} \mathrm{O}_{\mathrm{y}}$ oxides comprise this population. The same compositional results were associated with the larger inclusions distributed throughout the NiTi matrix, with dimension $<5 \mu \mathrm{m}$, as indicated by the arrows of Fig. 2a. EDX microanalysis results of particulates (see Fig. 4a) do not show any $\mathrm{C}$ signal according to the low $\mathrm{C}$ content measured in PAM alloy reported in Table 1.

A different particulates distribution and type of inclusions were observed in the VIM alloy as depicted in Fig. 2b. A uniform distribution of small particulates, mainly oxides, with the presence of several larger TiC inclusions, with size ranging from 5 to $40 \mu \mathrm{m}$, can be observed. The latter TiC inclusions are usually fractured throughout NiTi cold working steps as also reported in [23, 24].

From microstructure results, it is confirmed that the noncontaminating nature of the PAM melting route is suitable for the production of NiTi with an adequate microstructure and refined particle distribution. EDX spectra of typical inclusions and the NiTi matrix of both PAM and VIM alloys are reported in Fig. 3.

The micro-cleanliness of the purest PAM NiTi alloy was also evaluated according to ASTM F2063-12: the samples were viewed with backscattered electrons at $500 \times$ magnification and several images were collected, inspecting a total area of more than $2 \mathrm{~mm}^{2}$. In order to evaluate the number and total area of inclusions, selected fields of view were analyzed with image analysis software (X-Plus, Alexasoft ${ }^{\mathrm{TM}}$ ). The statistical outcomes for PAM are in fully compliance with the ASTM F2063-12 and the particles size distributions are presented in Table 2 and Fig. 4, respectively. In all fields of view, no particle with size greater than $39 \mu \mathrm{m}$ was found, and $1.73 \%$ (area \%) of total particles was evaluated. These results are in agreement with the industrial NiTi alloys statistical inclusion
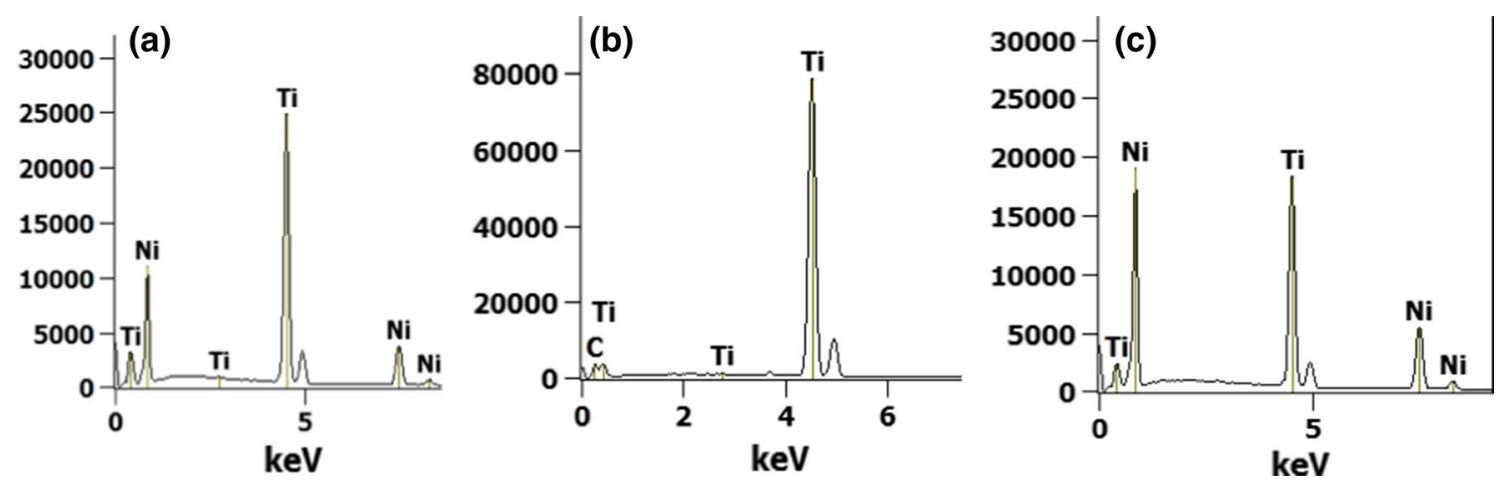

Fig. 3 EDX spectra of a typical inclusions of PAM NiTi; b typical inclusion of VIM NiTi; $\mathbf{c}$ NiTi matrix of both NiTi PAM and VIM showing near equiatomic NiTi composition 
Table 2 Statistical analysis results of standard purity PAM NiTi particulates

\begin{tabular}{ll}
\hline & PAM NiTi \\
\hline Image magnification & $500 \times$ \\
$\mathrm{N}^{\circ}$ field & 12 \\
Total sampling area $\left(\mu \mathrm{m}^{2}\right)$ & $484^{\prime} 380$ \\
$\left(\mathrm{~mm}^{2}\right)$ & 0.4844 \\
Total $\mathrm{N}^{\circ}$ particles & 9642 \\
Mean particle area $\left(\mu \mathrm{m}^{2}\right)$ & 1.04 \\
Total particles area $\%$ & 1.73 \\
Max particle size $(\mu \mathrm{m})$ & 28.14 \\
\hline
\end{tabular}

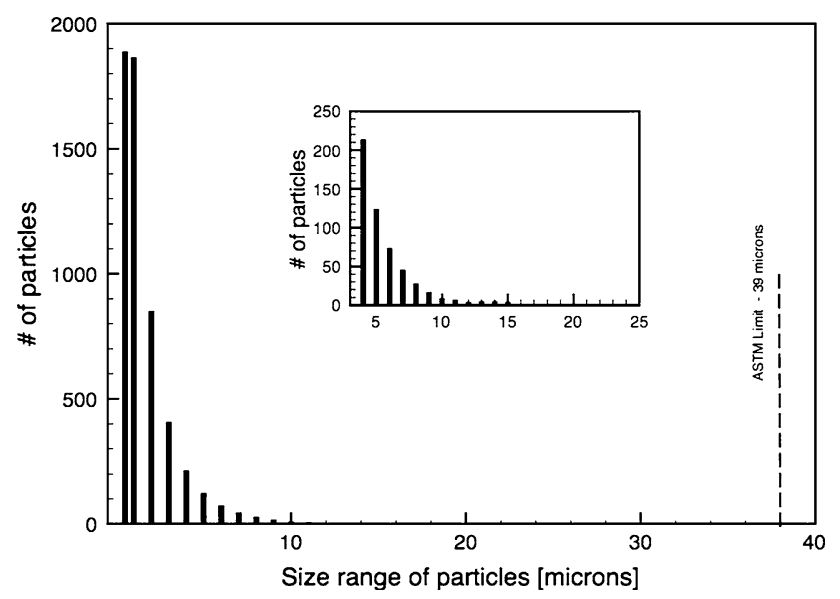

Fig. 4 Particle size distribution of PAM NiTi. Most of inclusions are characterized by a small size $(<3 \mu \mathrm{m})$, and particle larger than $19 \mu \mathrm{m}$ was not detected (see subview). The ASTM F2063-12 size limit of $39 \mu \mathrm{m}$ (dashed line) was depicted also distributions reported in Coda et al. [5] confirming that PAM is a suitable melting route for the production of Nitinol for medical devices and surgical tools.

\section{Corrosion tests}

Potentiodynamic polarizations curves of different surface preparations of PAM NiTi specimens are plotted in Fig. 5. As shown, the $1 \mu \mathrm{m} \mathrm{MP}$ and the $1 \mu \mathrm{m}$ EP samples show the same polarization behavior with pitting at high potential values ( $>1100 \mathrm{mV}$ vs SCE). This happens in metallic materials completely passivized by an un-cracked protecting layer. It should be remarked that for these specimens the increasing current, is due to oxygen evolution reaction rather than pitting phenomena, as verified by the fact that the specimens do not show the presence of attacks at the end of the tests. From the polarization curves shown in Fig. 5, the role of the surface condition on pitting potential is also highlighted. In fact, $\mathrm{E}_{\text {pit }}$ increases from 600 to $1100 \mathrm{mV}$ vs SCE as the surface finish changes from \#600 MP to $1 \mu \mathrm{m}$ MP (or after surface EP). The latter results on PAM alloy are in agreement to the Burstein et al. results $[25,26]$ asserting that rougher surfaces may create more vulnerable sites to corrosion compared to smoother surfaces. Furthermore, the high $\mathrm{E}_{\text {pit }}$ values measured for the $1 \mu \mathrm{m}$ MP and $1 \mu \mathrm{m}$ EP samples confirmed that a protective $\mathrm{TiO}_{2}$-enriched thin layer is created on EP surfaces, as reported by several authors [27-32]. It has been asserted that electro-polishing of Nitinol assures, on one hand, very smooth, defect-free surfaces and on the other hand promotes the formation of a very thin protective $\mathrm{TiO}_{2}$ layer ( $\approx 2 \mathrm{~nm}$ in thickness).
Fig. 5 Potentiodynamic tests in SBF $37{ }^{\circ} \mathrm{C}$ of MP and EP polished PAM NiTi alloy

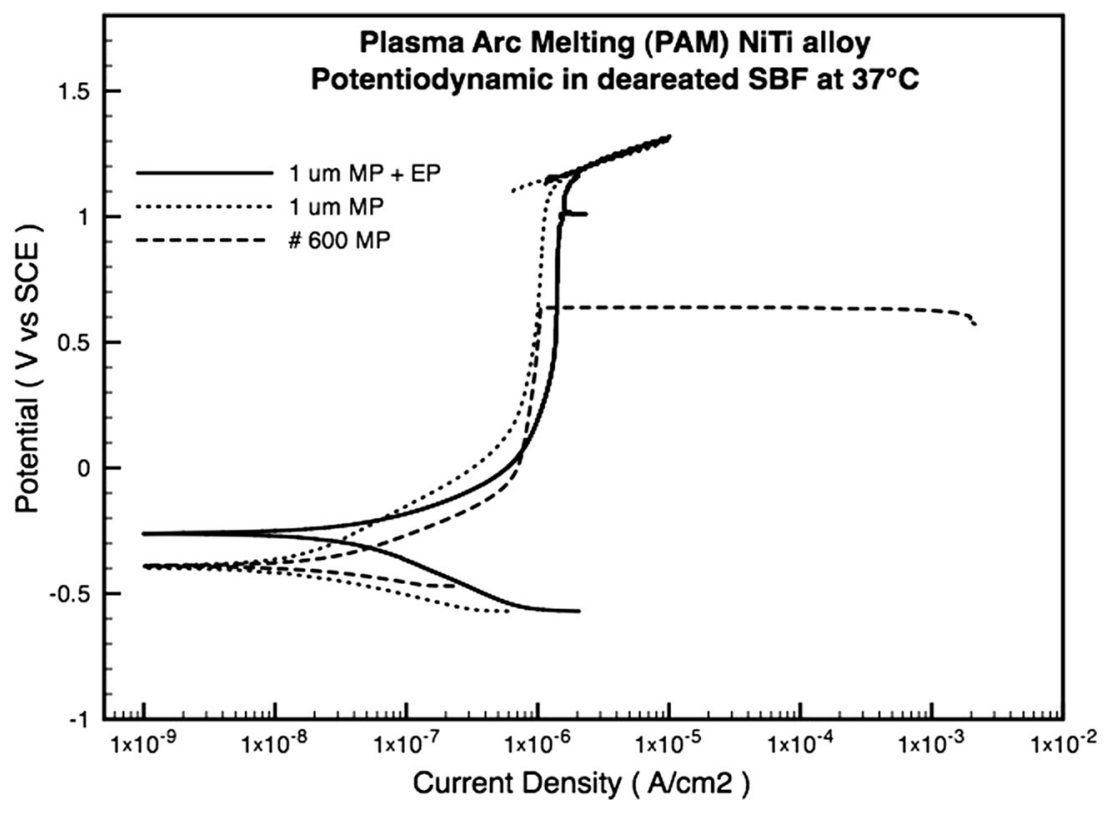


Fig. 6 Potentiodynamic tests in SBF at $37{ }^{\circ} \mathrm{C}$ of MP polished PAM and VIM NiTi alloys

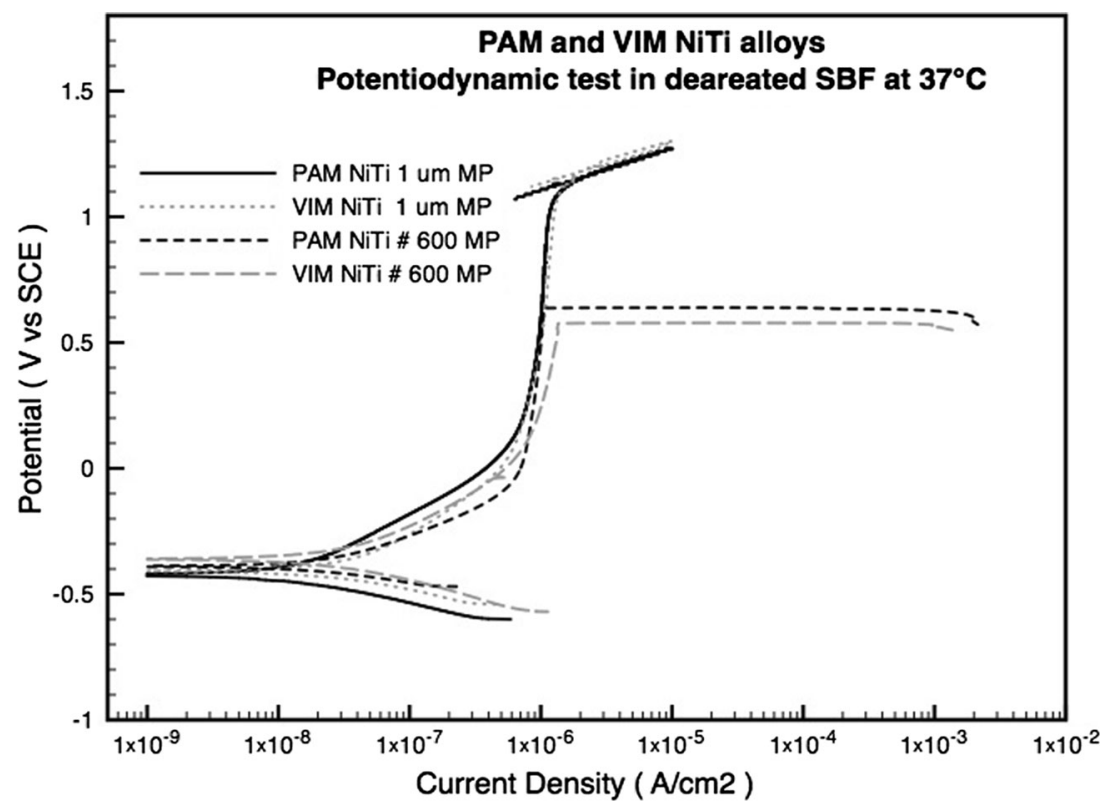

Table 3 Pitting potentials ( $\mathrm{mV}$ vs. SCE) of $1 \mu \mathrm{m}$ MP specimens

\begin{tabular}{lll}
\hline & Potentiodynamic test & Potentiostatic scratch test \\
\hline PAM NiTi & $>800$ & $300 \pm 10$ \\
VIM NiTi & $>800$ & $240 \pm 10$ \\
AISI 316L & $410 \pm 30^{\mathrm{a}}$ & $380 \pm 10^{\mathrm{a}}$ \\
Ti6Al4 V & $>800^{\mathrm{a}}$ & $>800^{\mathrm{a}}$ \\
\hline
\end{tabular}

a From Ref. [33]

In Fig. 6, a comparison of potentiodynamic polarization scans of PAM and VIM alloys are reported. From these plotted curves, it is unmistakable revealed that the NiTi alloys characterized by two different amount of inclusions show the same corrosion resistance behavior. Thus, from potentiodynamic tests, the correlation between the amount of inclusions, related to the purity degree of a NiTi alloy, and the corrosion resistance does not represent a reasonable approach for evaluating the acceptance of Nitinol purity degree. These results agreed the ones by Bai et al. [27] where any correlation between $\mathrm{Ti}_{2} \mathrm{NiO}_{x}$ inclusions and the resistance to pitting was not found.

In Table 3, the pitting values of the potentiostatic scratch tests conducted on PAM and VIM NiTi alloys are collected together with the potentiodynamic results and with similar testing results on AISI 316 and Ti6Al4 V reported elsewhere [33]. The potentiostatic tests of PAM and VIM alloys show comparable $\mathrm{E}_{\mathrm{pit}}$ values with the PAM alloy slightly greater (300 $\mathrm{mV}$ vs. SCE) than VIM alloy. These values are comparable to those for AISI $316 \mathrm{~L}$, while Ti alloys show greater potentiostatic pitting potential $(>800 \mathrm{mV}$ vs. SCE)
Table 4 Acceptance criteria based on pitting values of potentiodynamic polarization tests of implantable medical devices

\begin{tabular}{ll}
\hline$E_{\mathrm{p}}<300(\mathrm{mV}$ vs. SCE) & Unacceptable \\
$E_{\mathrm{p}} 300 \pm 600(\mathrm{mV}$ vs. SCE) & Marginal risk \\
$E_{\mathrm{p}}>600(\mathrm{mV}$ vs. SCE) & Acceptable \\
\hline
\end{tabular}

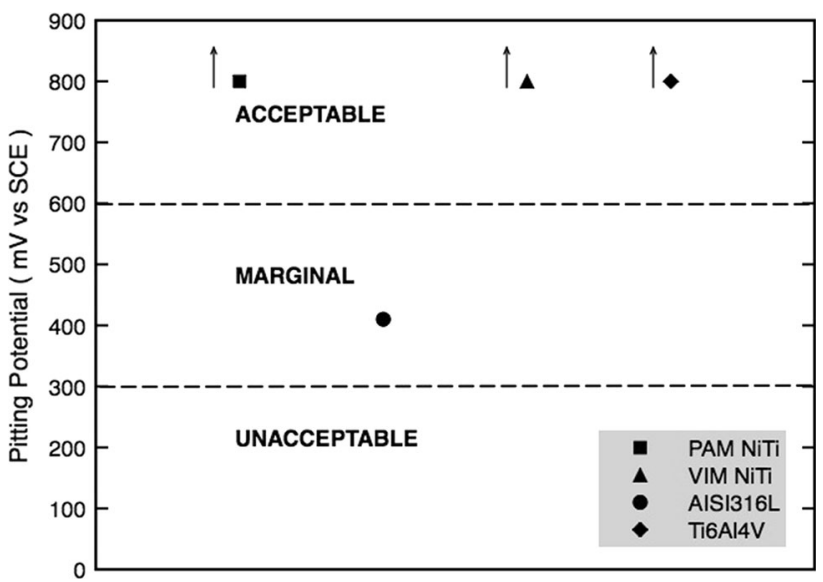

Fig. 7 Results of potentiodynamic tests re-plotted according to the classification of Rosenbloom and Colbert [36]. The value referring to Ti6Al4 V and AISI 316L stainless steel is taken from a previous work [33]

indicating a superior corrosion resistance. This result is in agreement with those of Vengupoland and Trepanier [34].

It must be emphasized that there is still an open question on acceptable criteria for corrosion resistance of implantable medical metallic devices. This matter is subjected to the ASTM F2129-08 Standard specifications [35]. Presently, this method for conducting cyclic potentiodynamic 
polarization measurements to determine the corrosion susceptibility of small implant devices does not specify any "acceptance criteria" for such devices. Rosenbloom and Colbert [36] proposed first an acceptance criterion based on results of potentiodynamic polarization tests as described in the ASTM F2129-08. In Tab. 4, their proposed classification is summarized (Table 4).

Following potentiodynamic tests required by this proposed criteria the results of the present work are re-plotted in Fig. 7. As seen, both the standard purity PAM alloy as well as low purity VIM NiTi could be accepted as implantable medical devices.

\section{Conclusion}

PAM was successfully employed to produce NiTi shape memory alloys. Non-metallic impurities in PAM alloy are consistent with the raw materials thus demonstrating the non-contaminating NiTi alloying process.

In vitro corrosion resistance tests of Nitinol with different inclusions content produced by PAM and VIM were reported. Potentiodynamic test did not show any effect of inclusions on the polarization curves, while the expected strong outcome related to sample surface preparation was highlighted.

The potentiodynamic results demonstrated that for EP and $1 \mu \mathrm{m}$ MP surface preparations, high pitting values $>800 \mathrm{mV}$ versus SCE were reached independently from the inclusions content. In this case, both the alloys show excellent corrosion resistance.

For rough \# 600 MP surface, Nitinol pitting value of about $600 \mathrm{mV}$ versus SCE was detected for both NiTi inclusions contents. That it could be considered as borderline value for acceptance of NiTi as implantable material as proposed classification.

For PAM and VIM, Nitinol potentiostatic polarization results showed lower pitting potentials $250-300 \mathrm{mV}$ vs SCE. In this case, the purer NiTi alloy showed slightly better corrosion resistance compared with the lower quality, but comparable to AISI $316 \mathrm{~L}$.

\section{References}

1. Shabalovskaya S, Anderegg J, Van Humbeeck J (2008) Recent observations of particulates in Nitinol. Mater Sci Eng A 481-482:431-436

2. Kimura H, Sohmura T (1987) Surface coating on TiNi shape memory implant alloys. J Osaka Univ Dental Scholl 27:211-223

3. Shabalovskaya S, Anderegg J, Van Humbeeck J (2008) Critical overview of Nitinol surfaces and their modifications for medical applications. Acta Biomater 4(3):447-467. doi:10.1016/j.actbio. 2008.01.013
4. Liang C, Huang N (2009) Electrochemical characteristic of TiNi shape memory alloy in artificial body fluids. J Biomed Mater Res A 89(1):266-269

5. Coda A, Zilio S, Norwich D, Sczerzenie F (2012) Characterization of inclusions in VIM/VAR NiTi alloys. JMEPEG 21:25722577

6. Urbano MF, Coda A, Beretta S, Cadelli A, Sczerzenie F (2013) The Effect of Inclusions on Fatigue Properties for Nitinol, Fatigue and Fracture of Medical Metallic Materials and Devices, 2013, STP 1559. http://www.astm.org. doi:10.1520/STP1559201 20189

7. Morgan N, Wick A, DiCello J, Graham R (2006) Proceedings of the SMST 2006, Pacific Grove, California Ed. Berg B, Mitchell MR, Proft J, 2006, pp 821-828

8. Rahim M, Frenzel J, Frotscher M, Pfetzing-Micklich J, Steegmuller R, Wohlschlogel M, Mughrabi H, Eggeler G (2013) Impurity levels and fatigue lives of pseudoelastic NiTi shape memory alloys. Acta Mater 61:3667-3686

9. ASTM F2063-12 (2012) Standard specification for wrought nickel-titanium shape memory alloys for medical devices and surgical implants. ASTM International, West Conshohocken

10. Knight R, Smith RW, Apelian D (1991) Application of plasma arc melting technology to processing of reactive metals. Int Mater Rev 36(6):221-252

11. Johnson TP, Jesper NE, Young JM, Ward RM, Jacobs MH (1993) The microstructure of plasma arc cold-hearth melted Ti-48Al2Mn-2Nb. J Phys IV. doi:10.1051/jp4:1993758

12. Stumpp $\mathrm{H}$ et al (1989) Advanced production of superalloy and titanium ingots by cold hearth melting. SAMPE J 25(3):21-26

13. Buttrill WH, Hunter GB, Shamblen CE, Melting Hearth (1993) Hearth melting of titanium alloys for aircraft engine applications. Metallurgy and technology of practical titanium alloys. TMS, Warrendale

14. Wightman P, Hensberger E (1991) Cold hearth refining of special metals. Met Mater 7(11):676-681

15. Chinnis WR (1990) Plasma Cold Hearth Melting of Titanium. In: Bakish R (ed) A production furnace, electron beam melting and refining state of the art. NJ, Englewood, pp 128-134

16. Coluzzi B, Biscarini A, Mazzolai G, Mazzolai FM, Tuissi A (2004) Scripta Mater 51:199-202

17. Besseghini S, Villa E, Tuissi A (1999) Mater Sci Eng A 273-275:390-394

18. Tuissi A, Besseghini S, Masini R, Cito F, Carcano G, Olzi E (1997) Plasma melting of supercontucting NbTi alloys. Vuoto Sci Technol 26:10-13

19. Besseghini S, Tuissi A, Olzi E, Cito F, Carcano G (1997) Melting of NiTi based shape memory alloys. Vuoto Sci Technol 26:5-9

20. ASTM G5-14 (2014) Standard reference test method for making potentiodynamic anodic polarization measurements. ASTM International, West Conshohocken

21. ASTM G61-86(2014), Standard test method for conducting cyclic potentiodynamic polarization measurements for localized corrosion susceptibility of iron-, nickel-, or cobalt-based alloys

22. Pessal N, Liu C (1971) Electrochim Acta 16:1987

23. Tuissi A et al (2004) Fabrication process and characterization of NiTi wires for actuators, Proceedings of SMST 2004, BadenBaden, Germany, pp. 501-508

24. Casati R, Tuissi A, Belochapkine S, Dickinson C, Tofail SAM (2012) Thin NiTi wires with reduced thermal hysteresis for shape memory actuators. Funct Mater. Lett. 5:1250009

25. Burstein GT, Pistorius PC (1995) Surface roughness and the metastable pitting of stainless steel in chloride solutions. Corrosion 51(5):380-385

26. Burstein GT, Burstein SP (2001) Vines repetitive nucleation of corrosion pits on stainless steel and the effects of surface roughness. Electrochem Soc 148(12):B504-B516 
27. Bai Z, Rotermund H (2011) Assessing the corrosion behaviour of nitinol for minimally-invasive device design. J Biomed Mater Res B Appl Biomater 99B(1):1

28. Admedes S (2004) Boundary for the use of Nitinol in medical applications, SMST 2004 Proceedings, October 3-7, 2004, Baden-Baden, Germany, Mertmann M (ed) ISBN:0-87170-8345 pp 563-571

29. Wu W, Liu X, Han H, Yang D, Lu S (2008) Electropolishing of NiTi for improving biocompatibility. J Mater Sci Technol 24(6):926

30. Cissè $\mathrm{O}$, Savadogo $\mathrm{O}, \mathrm{Wu} \mathrm{M}$, Yahia LH (2002) Effect of surface treatment of NiTi alloy on its corrosion behavior in Hanks' solution. J Biomed Mater Res 61(3):339

31. Pound BG (2002) Susceptibility of Nitinol to localized corrosion. J Biomed Mater Res A 77A:185

32. Eiselstein LE, Duane S, Nissan A, Corlett N, Dugnani R, Kus E, Stewart SG (2009) Acceptance criteria for corrosion resistance of medical devices: statistical analysis of nitinol pitting in in vivo environments. JMEPEG 18:768-780

33. Rondelli G, Vicentini B, Cigada A (1990) The corrosion behaviour of nickel titanium shape memory alloys. Corr Sci 30(8/ 9):805-812

34. Venugopalan R, Trepanier C (2000) Assessing the corrosion behaviour of nitinol for minimally-invasive device design. Min InvasTher Allied Technol 9(2):67-74

35. ASTM F2129-08 (2008) Standard test method for conducting cyclic potentiodynamic polarization measurements to determine the corrosion susceptibility of small implant devices. ASTM International, West Conshohocken

36. S.N. Rosenbloom, R.A. Corbett, An Assessment of ASTM F 2129 Electrochemical Testing of Small Medical Implants Lessons Learned, NACE Conference, 2007, Paper 07674 